\title{
Manufacturing As A Center For The Creation Of Shareholder Value
}

\author{
Darryl G. Waldron, Trinity University, USA
}

\begin{abstract}
A sample of the best manufacturing firms from Industrial Week's Annual Survey of Manufacturers (2008-2009) is analyzed within the context of a value driver matrix and free cash flow regime that link manufacturing to important determinants of shareholder value. The framework for analysis developed in association with this analysis relies on the format advocated by Rappaport (1998), whereby a manufacturing value driver map is derived that isolates those variables generally accepted as determinant with respect to manufacturing performance. This map is subsequently used to identify that subset of variables that have the greatest impact on value and, in turn, to focus on those micro-value drivers over which operations management has a meaningful level of control. If superior performance measured in terms of the micro-value drivers is an avenue to manufacturing excellence and the creation of shareholder value, one would expect to see statistically significant relationships between these predictor variables (micro-value drivers) and market value. Here this proposition is tested by way of a simultaneous reverse entry multiple regression analysis where market capitalization $\left(V_{0}\right)$ is treated as a function of a set of manufacturing related micro-value drivers.
\end{abstract}

Keywords: Micro-value drivers; degree of manufacturing leverage; incremental manufacturing cash outflow rate; capital intensity; free cash flow to the firm; reverse entry multiple regression

\section{INTRODUCTION}

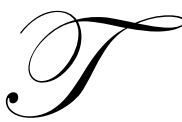

he creation of shareholder value has become the standard by which all companies are judged, and one of the greatest strategic challenges management faces in growing shareholder value is to balance the need for cost efficiency with the countervailing need to accommodate product diversity and market responsiveness. The significance of this competitive imperative is underscored by Bartlett and Ghoshal (1989) in their well regarded examination of transnational strategy:

In today's environment, competitive conditions are so intense that to survive in the global marketplace, firms must exploit experience-based cost economies and location economies, they must transfer distinctive competencies within the firm, and they must do all of this while paying attention to pressures for local responsiveness (p. 13).

At one extreme in this struggle for global competitiveness are firms pursuing a strategy designed to achieve global cost efficiency through the centralization of manufacturing, product standardization, and the amortization of the higher fixed costs characteristic of such a strategy over industry leading volume in order to minimize per unit costs. At the other extreme are firms pursuing a market segmentation and product differentiation strategy that necessitates a strong local market presence to leverage national differences that are of significance in the design of both its products and its value-chain(s). Here, manufacturing efficiency depends on taking full advantage of economies of scope where the relatively higher per-unit costs are offset by the higher returns to flexibility, customization and local market idiosyncrasies. This research examines the process by which the firm creates value for its shareholders, manufacturing's role in this process as an element of the firm's value chain and, through a multiple regression analysis of the best manufacturing firms from Industrial Week's Annual Survey of Manufacturers, identifies those manufacturing related micro-value drivers that are statistically significant determinants of shareholder value. 
Modern manufacturing strategy is designed to balance global efficiency with flexibility and responsiveness by optimizing the allocation of value adding activities geographically and organizationally. By viewing the allocation process as one would a multidimensional puzzle, elements of the firm's value chain, such as manufacturing, are scattered around the globe in a manner that allows for the maximization of value added on an element-by-element basis while simultaneously taking advantage of global economies of scale and location achieved through system design economies and synergy. The firm ends up being organized around activities where it has a core competence and around "centers of excellence" that provide access to outside suppliers with core competences that can be used to fill gaps in the firm's value chain. The objective is to create an overall level of competence that produces more value added than would be possible given any other configuration of organic and non-organic value chain activities. Put more precisely, what management is faced with is solving a globally distributed constraint optimization problem that leads to the overall maximization of value added through manufacturing. Firms with a broader set of competences in manufacturing will produce more of the product, while those with less manufacturing breadth will buy more from outside suppliers and be more "assembler like" in both form and function. In fact, it is this strategic duality that has made the make versus buy decision such an important determinant of the value added by manufacturing.

Here the best test of success in creating a value chain that is optimal is the extent to which it contributes to the firm's ability to grow shareholder value over an extended period of time at above market and industry rates. Such performance would not be possible on a sustained basis if the firm were wedded to a value chain and manufacturing strategy that were suboptimal. This is true because free cash flow to the firm, which drives intrinsic and in turn market value, is a function of value added. Manufacturing's contribution to this process derives from its ability to engage in an optimal mix of value adding activities and, in so doing, facilitate company-wide efforts to achieve both industry and market leading performance when measured in terms of the firm's value drivers (i.e., sales growth rate, operating profit margin, marginal rate of taxation, working and fixed capital reinvestment rates, cost of capital, and value growth duration) and, in turn, the creation of shareholder value, the standard by which both managers and their companies are judged (Rappaport, 1998). Manufacturing outcomes should be judged on the basis of the contribution they make to this process.

Operationalizing the shareholder value model at the functional level, however, requires that management move from a macro to a micro orientation, a transition that is complicated in some instances by a lack of measurability, in other instances by a lack of information, and in still others by an organizational design that obscures critical underlying relationships that make control of micro-value drivers more difficult. The framework for analysis developed in association with this analysis relies on the format advocated by Rappaport (1998), whereby a manufacturing value driver map is derived that isolates those variables generally accepted as determinant with respect to manufacturing performance. This map is subsequently used to identify that subset of variables that have the greatest impact on value and, in turn, to focus on those micro-value drivers over which operations management has a meaningful level of control. In this process, one will invariably encounter value drivers such as currency exchange rates, energy costs and the availability of critical raw materials that impact manufacturing performance but over which management has only limited control. As suggested below, these influences are not ignored but they are managed differently.

This study is based on a multiple regression analysis of the top ranked firms from Industrial Week's Annual Survey of Manufacturers. As discussed below, the sample size of 162 observations was more than sufficient to produce a ratio of observations to variables beyond the minimum requirement of at least 10 (Hair, Anderson and Tatham, 1987). Market capitalization $\left(V_{0}\right)$ was treated as a function of the following predictor variables (micro-value drivers):
- $\quad \mathrm{CGS} \%=$ Cost of goods sold/Net sales
- $\quad \mathrm{DML}=\% \Delta$ Gross profit $\% \Delta$ Net sales
- $\quad$ IT $=$ Cost of goods sold/inventory
- $\quad \mathrm{e}_{\mathrm{I}}=\% \Delta$ Inventory $/ \% \Delta$ Net sales
- $\quad \mathrm{CI}_{\mathrm{P} \& \mathrm{E}}=$ Plant $\&$ equipment net of depreciation/Net sales
- $\quad \mathrm{FAT}=$ Net sales/Plant $\&$ equipment net of depreciation
- $\quad \mathrm{IMCO}=\left(\Delta \mathrm{CGS}+\Delta \mathrm{I}+\Delta \mathrm{P} \& \mathrm{E}_{\mathrm{NET}}\right) / \Delta$ Net sales 
While these metrics are, for the most part, well understood measures of manufacturing performance, what is not as well understood is the extent to which they impact shareholder value and the pathways by which this occurs. A fundamental proposition of the shareholder value model is that management should not waste its time with variables over which it has little or no control and should instead focus on those variables that are both controllable and determinant with respect to the creation of economic value. This is not to suggest that managers are to ignore those factors that cannot be directly controlled, but that they use alternative methods, such as hedging to manage such exposure. This line of reasoning is consistent with the decision theory underlying management of the economic and transaction exposure that attaches to commodities and foreign currencies. This decision-making process is described graphically in Figure 1.

Figure 1: Micro-Value Driver Matrix

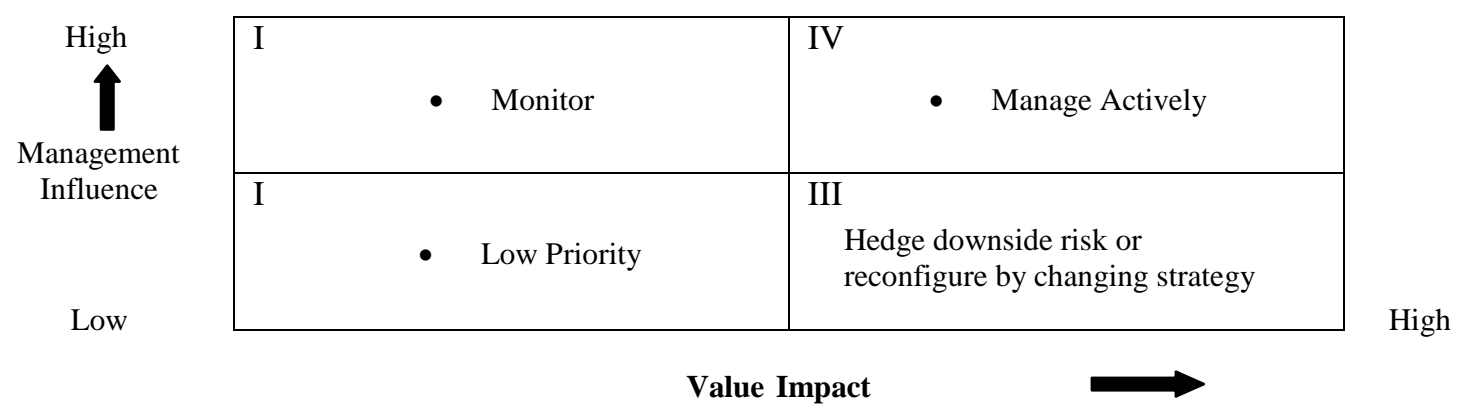

The challenge management faces is that the array of variables that impact manufacturing performance is extensive and cluttered with variables that only require passive monitoring or that may be prioritized against goals other than value creation. Valuable resources are marshaled to increase market share, maintain pricing, increase distribution, introduce new products, increase operating efficiency, etc. without a clear sense of what really leads to the creation of economic value as opposed to simply generating better accounting based measures of performance. The "Micro-Value Driver Matrix" represents a framework for prioritizing a firm's real value drivers based on their level of significance and the extent to which they need to be actively or passively managed. The task facing management is to identify variables which reside in quadrant IV and to actively manage those variables in such a way that shareholder value is maximized while simultaneously managing in a less active fashion those resources and activities that more directly influence variables in quadrants I through III. The research undertaken here addresses this task by introducing a regimen by which statistically significant manufacturing micro-value drivers can be identified and their underlying role in creating shareholder value measured.

The logic underlying specification of the regression model used for the analysis draws on well established principles of both manufacturing and finance (Copeland, Koller and Murrin, 2000; Fry, 1992; Maskell, 1991; Parmenter, 2007; Rappaport, 1998; Roth and Miller, 1992; and Merkel, 1995). The research design called for a predictor set derived from non-proprietary and readily available data that would produce useful results in terms of both external analysis and managerial decision making. The overriding objective was to be left with a model that was both parsimonious in its specification and robust in its ability to explain changes in a firm's market value based on the variance of seven manufacturing micro-value drivers. Following is a brief discussion of the anatomy of each of those predictor variables (micro-value drivers):

- $\quad$ Cost of goods sold is composed entirely of charges related to manufacturing (direct labor, material and overhead) and tends to vary directly with changes in the level of activity (sales). One would expect higher levels of manufacturing efficiency to be associated with a lower cost of goods sold to sales ratio (CGS\%).

- $\quad$ The degree of manufacturing leverage (DML) measures the extent to which changes in gross profit are elastic with respect to changes in sales. Here, higher levels of manufacturing efficiency (i.e., a lower rate of growth in CGS relative to growth in sales) would produce a DML greater than one, with higher levels of manufacturing efficiency resulting in higher rates of growth in gross profit (sales - CGS) relative to growth in sales. 
- Inventory turnover derived using CGS (CGS/I) rather than sales adjusts for the upward bias caused by the markup on cost. Since inventory accounts for raw material, work in process and finished goods, it captures either directly or indirectly the consequences of various best practices in inventory management (Barry, 2007).

- A related measure that captures the extent to which management is effective in harmonizing growth in inventory with growth in sales is $\mathrm{e}_{\mathrm{I}}(\% \Delta$ Inventory $/ \% \Delta$ Net sales $)$, which measures changes in inventory levels with respect to sales. Since investment in inventory is a function of growth in sales, one would expect better inventory management to yield an $\mathrm{e}_{\mathrm{I}}$ equal to one and the greater the divergence from one the less effective inventory management.

- $\quad$ Plant and equipment intensity $\left(\mathrm{CI}_{\mathrm{P} \& \mathrm{E}}\right)$ measures the investment in plant and equipment necessary to generate one dollar of revenue. One would expect an optimal level of investment and mix of assets that are fully utilized and properly maintained to result in consistently lower levels of $\mathrm{CI}_{\mathrm{P \& E}}$.

- $\quad$ An additional metric that is closely related to $\mathrm{CI}_{\mathrm{P} \& \mathrm{E}}$ is a firm's fixed asset (plant and equipment) turnover ratio (FAT), a measure that derives from the rate at which management is able to convert investment in manufacturing assets into sales.

- $\quad$ Finally, the incremental manufacturing cash outflow rate (IMCO) measures management's ability to control manufacturing cash outflows associated with changes in the level of operating activity. A higher IMCO rate would tend to compromise the firm's ability to grow value because of higher direct manufacturing costs, inventory levels and capacity relative to sales.

The fully specified regression model may be expressed as follows:

$V_{0}=a \pm b_{t}\left(x_{t n}\right) \pm b_{j}\left(x_{j n}\right) \pm b_{k}\left(x_{k n}\right) \pm b_{l}\left(x_{l n}\right) \pm b_{m}\left(x_{m n}\right) \pm b_{n}\left(x_{n n}\right) \pm b_{o}\left(x_{o n}\right)+e$

where:

$b_{t}\left(x_{t n}\right)=$ beta coefficient/predictor for cost of goods sold/net sales

$b_{j}\left(x_{j n}\right)=$ beta coefficient/predictor for $\% \Delta$ gross profit $/ \% \Delta$ net sales

$b_{k}\left(x_{k n}\right)=$ beta coefficient/predictor for cost of goods sold/inventory

$b_{l}\left(x_{l n}\right)=$ beta coefficient/predictor for $\% \Delta$ inventory $/ \% \Delta$ net sales

$b_{m}\left(x_{m n}\right)=$ beta coefficient/predictor for plant \& equipment net of depreciation/Net sales

$b_{n}\left(x_{n n}\right)=$ beta coefficient/predictor for net sales/plant \& equipment net of depreciation

$b_{o}\left(x_{o n}\right)=$ beta coefficient/predictor for $\left(\Delta C G S+\Delta I+\Delta P \& E_{N E T}\right) / \Delta$ Net sales

$e=$ unexplained variance

\section{REVIEW OF THE LITERATURE}

Not unlike the other functional areas of business, the literature pertaining to manufacturing is characterized by multiple genres and among some, considerable overlap. The analysis undertaken here focuses on the measurement of manufacturing performance but within that context it focuses even more directly on a very lightly researched yet highly important segment of the measurement genre, the underlying relationship between manufacturing performance and the creation of shareholder value. As such, this review provides an overview of the existing scholarship and an index of the extent to which the research undertaken here fills a void in the existing literature.

Until mid-century, the path to competitive advantage in manufacturing was to a very great extent a story about vertical integration, significant capital investment, returns to scale, and the quest for high degrees of operating 
leverage (Wise and Baumgartner, 2007). In the 1970s, the Japanese ushered in a new era in manufacturing that called into question time-honored manufacturing practices with the introduction of such strategies as lean manufacturing, outsourcing and flexible manufacturing dedicated to achieving both economies of scale and scope. For many firms, the "make decision" became the "make or buy" decision; new ways of thinking about and evaluating manufacturing systems and processes emerged and new metrics appeared to measure manufacturing performance.

Commenting on the evolution of manufacturing strategy and policy, Hayes and Pisano (1994) argued that most Japanese companies producing products similar to Western firms but with fewer defects, greater reliability and more durability had a secret weapon and "their secret weapon turned out to be sheer manufacturing virtuosity." This enhanced ability to make things was in turn complemented by the development of new ways of organizing and integrating manufacturing systems and processes and of measuring and controlling manufacturing performance. In his highly regarded discussion of the "intellectual revolution" that attached to the emergence of manufacturing theory and practice, Drucker (1990) observed "The most exciting and innovative work in management today is found in accounting theory, with new concepts, new approaches, new methodology — even what might be called new economic philosophy-rapidly taking shape. And while there is enormous controversy over specifics, the lineaments of the new manufacturing accounting are becoming clearer every day." Here the byproduct of what became a cooperative effort involving multinational manufacturers, equipment and technology providers and cost accountants was the development of a new cost accounting system incorporating innovative ways of capturing and measuring manufacturing data.

There is a growing list of more narrowly defined strategic initiatives that are commonly used to identify world-class manufacturers. These characteristics are frequently referred to as "best-practices" and they have come to represent a core element in the literature pertaining to manufacturing and, more recently, supply-chain management. Unfortunately, the terminology is somewhat misleading because while best practices may play a part in improved manufacturing performance, it is clear that to do so they must be selectively employed and effectively implemented. In other words, best-practices are not universally applicable, even within an industry nor, even where they are applicable, should one expect them to be equally potent across applications (Harrison, 1998). Their potency is highly situational and implementation appears to be as important as the practice. The use of best practices to evaluate a company's manufacturing strategy has actually become a form of benchmarking that managers and analysts use to determine where a company stands relative to some index. Such benchmarking may be quantitative or qualitative. Quantitative benchmarking involves the use of metrics produced from best practices to compare actual performance with established world-class quality, time, and cost measures. Qualitative benchmarking seeks to compare current manufacturing practices to the practices of leading manufacturers. Qualitative benchmarking allows one to derive a "profile" of best practices as a basis for comparison much as Roger Smith did in comparing GM's manufacturing system with the best the Japanese had to offer (Drucker, 1990). Within the context of the firm's manufacturing strategy these practices are strung together to give the system a degree of robustness and virtuosity that it would not otherwise have. The whole idea is to integrate these practices into the firm's manufacturing strategy in a way that allows it to more effectively leverage any core competencies it may have and in so doing add more value through manufacturing than would be possible with any other system configuration. Of critical importance here is that management take a systems approach in balancing the use of capital, technology, and labor. Furthermore, to remain an effective competitive weapon, a firm's manufacturing system must assume an organic character, growing from within in response to organizational innovation while being quick to adopt worthwhile technology and ideas developed elsewhere. Below is list of more broadly adopted best practices commonly cited in the manufacturing literature. Again, it is important that a distinction is made between these very specific initiatives and the firm's overall manufacturing strategy, which may utilize a combination of these practices:

$\begin{array}{ll}\text { - } & \text { Agile manufacturing } \\ \text { - } & \text { Automatic storage/retrieval systems } \\ \text { - } & \text { Cenchmarking } \\ \text { - } & \text { Compular manufacturing } \\ \text { - } & \text { Computer-aided design } \\ \text { Computer-integrated manufacturing }\end{array}$




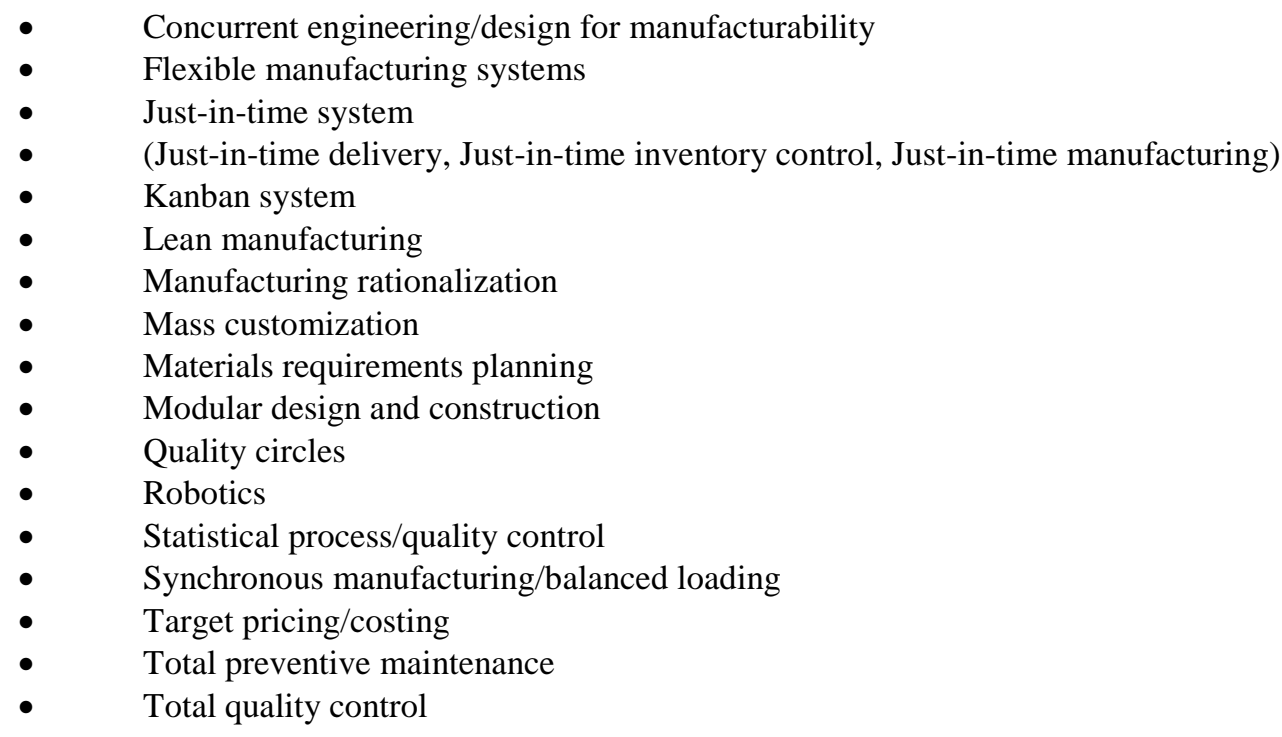

\section{"Best practices" in Manufacturing}

Among the many "best practices" that are commonly used by manufacturers, lean manufacturing has grown in popularity and as Epply (2004) and Maskell (2007) demonstrate, adoption of lean manufacturing has led to the development of a measurement and accounting regime characterized by an expanded array of metrics that target both traditional and nontraditional areas of manufacturing performance:

The goal of Lean Manufacturing is the creation of a "World Class" level of manufacturing operations metrics. The following chart shows typical world class manufacturing metrics:

\section{Measure}

Manufacturing Lead Time

Delivered Quality

Delivery Performance

Inventory Turns

Conversion Costs

Manufacturing Space

New Product Development

Skill Trades Response

Production Skilled Trades Ratio

Changeover Time

\section{Performance}

$<1$ day

3 PPM

$99+\%$

$>50$

$25-40 \%$ less than mass producers

$35-50 \%$ less than mass producers

$<6$ months

$<2$ minutes

$>20: 1$

$<$ TAKT Time

World Class is the goal that your competitors are striving to reach and what the very best have already attained (Epply, 2004).

While lean manufacturing is commonly viewed as a manufacturing best practice, in reality it is a composite of manufacturing best practices combined in such a way that they make a maximum contribution to the elimination of waste of all kinds. Beyond lean manufacturing, the array of best practices utilized by manufactures is extensive and evolving, assuming in many instances an almost proprietary nature as they are adapted to accommodate firm and even factory specific requirements (Brown and Bessant, 2003). These best practices often lead to the creation of proprietary metrics, a process that in association with lean manufacturing has given rise to Lean Accounting, a highly adaptive and creative approach to traditional manufacturing cost accounting. In conjunction with the further development of new ways of doing things and of measuring the outcomes, attention once again is being paid to just how such strategies and tactics are affecting and are affected by the behavioral climate. Chan (1993) argued that: 
"This holistic people-oriented approach recognizes that, although the world is increasingly driven by high technology, it continues to be influenced and managed by people (customers, workers, suppliers, distributors, competitors). More recently, Cua, McKone and Schroeder (2001) found evidence supporting the notion that Total Quality Management (TQM), Just-in-Time (JIT) and Total Productive Maintenance (TPM) lead to enhanced manufacturing performance when both their socially oriented practices and technically oriented practices are jointly emphasized. A result achieved by way of what Cua, McKone and Schroeder (2001) subsequently describe as an integrated dynamic performance measurement system (IDPMS), which integrates activity among management, dedicated process improvement teams, and the factory shop floor.

Maskell (2007) contends that lean accounting tools represent a "special case of measuring" that complements the normal functions of planning, measuring, costing, reporting, managing, and improving:

The over-all management system links business policy and decision making to external environmental changes through hoshin kanri and target costing. These in turn affect what should be measured and improved (measuring and improving) and reported in the financial results (costing and reporting). Improvements then feedback on the planning and measurement functions.

It is worth mentioning that the linkages described by Maskell (2007) are consistent with the framework and processes characterized by the micro-value driver matrix (see Figure 1) introduced as an element of the current analysis. Correspondingly, manufacturing performance that results from the pursuit of performance targets such as those identified by Epply (2004) becomes determinant where a firm's manufacturing related "micro-value drivers" are concerned. As such, this process is an example of the task facing management by way of identifying variables which reside in quadrant IV of the micro-value driver matrix and actively managing those variables in such a way that shareholder value is maximized.

Roztocki and Needy (1999) introduce a manufacturing cost and performance measurement system that integrates traditional activity-based costing (ABC) with economic value added (EVA). A hybrid approach that provides management with a tool to simultaneously measure and manage direct manufacturing costs and the related cost of the capital used to finance manufacturing investment, the Roztocki and Needy (1999) model measures manufacturing performance in terms of the rate of resource consumption and capital demand. While a traditional $\mathrm{ABC}$ system focuses on accounting for the cost of each manufacturing activity at the first stage of the creative process, the ABC-EVA system advocated by Roztocki and Needy (1999) uses Activity Capital Dependence (ACD) Analysis to transform first stage costs of manufacturing into "end product costs." Although EVA is a byproduct of free cash flow to the firm, free cash flow to the firm is a byproduct of much more than just manufacturing activity. As a consequence, one would need to adjust EVA for both the direct and associated capital charges related to other functional areas of the business. Furthermore, unlike the analysis undertaken here, Roztocki and Needy (1999) make no attempt to calculate manufacturing's contribution to the creation of shareholder value.

Modern manufacturing theory and practice have been broadly influenced by the growing need to be more environmentally responsible, an obligation that has given rise to increased investment in manufacturing sustainability and new ways of evaluating and measuring manufacturing performance. One area of manufacturing performance that has attracted particular attention is waste, a "cost of production" that has come to be viewed as a multidimensional construct that transcends the old notion that equated waste with scrap and the process of reworking. New ways of thinking about waste have given rise to new ways of thinking about and addressing old problems and new metrics to measure performance. In this regard, Epply (2004) goes so far as to define waste as "anything that does not add value to the customer. Once you have changed your mindset, you will see opportunity after opportunity for eliminating waste." Put in the context of the analysis undertaken here, one would expect a "no waste" manufacturing strategy and policy linked to the micro-value drivers for manufacturing to result in the creation of more shareholder value through improvements in the firm's value drivers and, in turn, free cash flow to the firm.

Shaw and Ward (2003), building on earlier work pertaining to contextual factors and the extent to which they "may present strong inertial forces within organizations that inhibit implementations that appear technically rational," examined the effects of plant size, plant age and unionization status on the likelihood of successfully 
implementing a variety of best practices that fall under the rubric of lean manufacturing. Shaw and Ward (2003) also considered the impact of what they describe as "four bundles of interrelated and internally consistent practices"just-in-time (JIT), total quality management (TQM), total preventive maintenance (TPM), and human resource management (HRM) on manufacturing performance, concluding that:

"The evidence provides strong support for the influence of plant size on lean implementation, whereas the influence of unionization and plant age is less pervasive than conventional wisdom suggests. The results also indicate that lean bundles contribute substantially to the operating performance of plants, and explain about $23 \%$ of the variation in operational performance after accounting for the effects of industry and contextual factors."

One of the most broadly utilized approaches for evaluating organizational effectiveness generally and manufacturing performance in particular is the balanced scorecard (Paranjape, Rossiter and Pantano, 2006). Depending on the performance measurements incorporated in the balanced scoreboard, it comes as close as any measurement system to having the potential to link shop floor performance and the creation of shareholder value. However, as Paranjape, Rossiter and Pantano (2006) point out, from a practical standpoint, successful implementations are much less prevalent and translating the balanced scorecard into concrete action is still a problematic area. Furthermore, Sweeney (1994) found that inappropriate choices of key manufacturing performance indicators were made by 50 per cent of the business units he studied and this was because of poor strategic vision for manufacturing operations. Also, evidence was found to show that 70 per cent of the firms studied needed a better understanding of their own processes before they could benefit from benchmarking other organizations. In fact, to effectively use a balanced scorecard system to evaluate manufacturing performance would require that precisely the same metrics associated with the micro-value driver matrix (see Figure 1), complemented by a potpourri of proprietary processes and measures, be used to assess manufacturing's contribution to overall performance. This notion is underscored by the research of Schroeder, Bates and Junttila (2002), which demonstrates that:

Competitive advantage in manufacturing (as measured by superior plant performance) results from proprietary processes and equipment which, in turn, is driven by external and internal learning. The implication is that resources such as standard equipment and employees with generic skills obtainable in factor markets are not as effective in achieving high levels of plant performance, since they are freely available to competitors.

The development and utilization of such proprietary measures is widely discussed in the manufacturing literature (Kyu and Park, 1987; Kald, and Nilsson, 2005; Chen, 2008). It is worth emphasizing that any of these metrics, as well as more conventional measures of manufacturing performance, could be utilized in association with the framework for analysis and micro-value drivers introduced in conjunction with the research undertaken here.

Perhaps the single feature that distinguishes the current research from earlier related work is the attention it pays to both the contribution manufacturing makes to the creation of shareholder value and to the pathways by which the process of value creation takes place. As this review of the literature pertaining to measuring and evaluating manufacturing performance suggests, creating shareholder value through better manufacturing has been largely ignored. In this regard, Christopher and Ryals (1999) probably come as close as anyone to investigating this relationship, but their focus is on the supply chain and "value based" management practices as an avenue to the creation of shareholder value and not on actually identifying manufacturing value drivers and measuring their contribution to shareholder value. Most of what might be called related research has dealt with the relationship between better manufacturing and improvements in various measures of financial performance such as return on equity, earnings per share and return in invested capital. Unfortunately, a firm can register outstanding performance in terms of commonly used accounting based measures of performance and yet not contribute in any significant way to the creation of shareholder value, the standard by which a firm's performance is ultimately judged. It is this error of omission that the following analysis addresses.

\section{RESEARCH DESIGN AND METHODOLOGY}

The group of 50 companies comprising the sample was chosen because their operating performance established them as industry leaders in terms of profitability and return on invested capital. Adjusted for missing data, the sample of 162 observations was of sufficient size to produce a ratio of observations to variables of 23 , well 
beyond the minimum requirement $(\geq 10$ ) necessary to justify utilizing a multivariate parametric technique (Hair, Anderson and Tatham, 1987). The data were subjected to a simultaneous reverse entry multiple regression analysis, where market capitalization $\left(V_{0}\right)$ was treated as a function of the firm's CGS\%, DML, IT, $\mathrm{e}_{\mathrm{I}}, \mathrm{CI}_{\mathrm{P \& E}}, \mathrm{FAT}$, and IMCO. The regression model produced here was derived from total variance, with the predictor variables entered in reverse order based on the percentage of total variance explained. This allows for assessment of the incremental variance accounted for by each variable, progressing from the least to the most significant predictor variable in terms of explanatory power. Again, market capitalization $\left(V_{0}\right)$ was derived on a year-end basis by multiplying the firm's closing share price by the year-end number of shares outstanding.

If superior performance measured in terms of the micro-value drivers is an avenue to manufacturing excellence and the creation of shareholder value, one would expect to see statistically significant relationships between these predictor variables (micro-value drivers) and market value. More directly, such relationships contribute to the enhancement of free cash flow to the firm, making it possible for the firm to earn a return on invested capital that exceeds its cost of capital and that is sufficient to create enough economic value to attract investment. Economic value obtains from a firm's ability to maximize the present value of free cash flow to the firm through the combined efforts of the various functional areas of the business, including manufacturing, by simultaneously combining revenue growth with higher levels of operating profit, lower marginal tax rates, lower reinvestment rates for both working capital and plant and equipment, and a lower cost of capital. Given this paradigm, excellence in manufacturing produces micro-value drivers that contribute to this process largely through a lower cost of goods sold, lower reinvestment rates, particularly in terms of inventory and plant and equipment, and because of these lower reinvestment rates, a lower demand for and cost of capital.

Average market capitalization $\left(V_{0}\right)$ for the sample firms was $\$ 52.9$ billion, ranging from a low of $\$ 13.4$ billion to a high of $\$ 153.5$ billion. The mean CGS\% was 66.2 percent, resulting in an average gross margin of profit among sample firms of 33.8 percent. The average degree of manufacturing leverage (DML), which reflects the rate at which gross profit could be expected to change with changes in sales, was 1.50, ranging from a low of -11.60 to a high of 43.90. Here one would like to see a DML above one and an average DML of 1.50 would imply that a 10 percent increase in revenue would result in a 15 percent increase in gross profit. The average inventory turnover rate (IT) among sample firms was 13.75, ranging from a low of below 1.0 to a high of 87.4. At an average IT of 13.75, a firm would need to invest approximately seven cents in inventory (i.e., finished goods, work in process and material) for each dollar of sales generated. The average inventory elasticity measure $\left(\mathrm{e}_{\mathrm{I}}\right)$ was 1.00 , which indicates that sample manufacturers tended to grow inventory at a rate commensurate with revenue growth, the kind of performance one would expect from leading manufacturers when viewed over time. An $\mathrm{e}_{\mathrm{I}}$ noticeably above or below 1.0 would suggest that the firm was either over or under investing in inventory relative to sales. The average $\mathrm{CI}_{\mathrm{PEE}}$, a measure of capital investment in plant and equipment relative to sales, was 21.4 cents, ranging from a low of 2.7 cents to a high of $\$ 1.50$ per dollar of sales. One strategy manufacturers have employed to reduce $\mathrm{CI}_{\mathrm{P \& E}}$ is, of course, the broader use of outsourcing. The average FAT was 7.86, ranging from a low of under one turn to a high of 36.6 turns, another micro-value driver that is strongly influenced by the level of outsourcing. Finally, the average IMCO, which measures total manufacturing related cash outflows (i.e., cost of goods sold plus incremental investment in inventory and plant and equipment) relative to sales, was 62.5 cents. Cash flows were not adjusted for the effect of taxation, a consequence largely influenced by financial strategy and policy. Table 1 presents a summary of selected descriptive statistics for each of the manufacturing micro-value drivers.

Table 1: Descriptive Statistics

\begin{tabular}{|l|c|c|c|c|c|c|c|c|c|}
\hline Statistics & $\mathbf{V}_{\mathbf{0}}$ & $\mathbf{C G S \%}$ & $\mathbf{D M L}$ & $\mathbf{I T}$ & $\mathbf{e}_{\mathbf{i}}$ & $\mathbf{C I}_{\text {P\&E }}$ & FAT & IMCO \\
\hline Mean & 52.92 & .6622 & 1.50 & 13.75 & 1.00 & .2138 & 7.87 & .6250 \\
\hline Median & 50.87 & .7270 & 1.08 & 8.19 & .9216 & .1495 & 6.68 & .8753 \\
\hline Std. Dev & 25.20 & .2019 & 4.03 & 13.87 & 3.49 & .2213 & 5.79 & 3.35 \\
\hline Minimum & 13.42 & .1516 & -11.60 & .5443 & -30.97 & .0273 & .6587 & -40.92 \\
\hline Maximum & 153.47 & .9330 & 43.90 & 87.37 & 17.79 & 1.52 & 36.63 & 3.56 \\
\hline Percentiles \\
\hline 25 & 33.35 & .5154 & .7677 & 5.16 & .2992 & .1047 & 4.43 & .6286 \\
\hline 50 & 50.87 & .7270 & 1.08 & 8.19 & .9216 & .1495 & 6.68 & .8753 \\
\hline 75 & 63.37 & .8209 & 1.46 & 18.12 & 1.60 & .2255 & 9.55 & 1.10 \\
\hline
\end{tabular}


Table 2 presents the results of the multiple regression analysis. Here the manufacturing micro-value drivers (CGS\%, DML, IT, $\mathrm{e}_{\mathrm{I}}, \mathrm{CI}_{\mathrm{P \& E}}, \mathrm{FAT}$, and IMCO) were regressed on market capitalization ( $\left.\mathrm{V}_{0}\right)$ using the SPSS REVERSE regime. Predictor variables were simultaneously entered into the multiple regression analysis, but this was done in reverse order based on the amount of variance explained by each predictor variable (micro-value driver). Where there is a statistically significant relationship between one or more of the predictor variables and the dependent variable, the standardized regression coefficient(s) can be used to identify which variable(s) account for significant amounts of the variance in the dependent variable $\left(V_{0}\right)$ and to explain or describe the nature of that variance. A conventional t-test was used to evaluate the explanatory power of the predictor variables, using criterion values of below -2 and above +2 and a significance level of .05 or below. While a variety of statistical tests are available to evaluate the explanatory power of the regression model, this analysis relied on a criterion F-ratio of .05 or below. The assumption of linearity was tested for and satisfied through diagramming. Again, the sample size was sufficient to produce a ratio of observations to variables well beyond the minimum requirement of at least 10 (Hair, Anderson and Tatham, 1987). The resulting Durbin-Watson statistic of 1.282 suggested the presence of some autocorrelation, a result that is not uncommon where one or more of the predictor variables share common elements. The resulting tolerance measures $(\mathrm{T})$ suggest that most of the multicollinearity present attached to two micro-value drivers, DML and IMCO. In general, a worrisome level of multicollinearity is signaled when a high $\mathrm{R}^{2}$ and significant $\mathrm{F}$ tests occur in combination with non-significant $\mathrm{t}$-tests, which was not the case here.

Table 2: Reverse Entry Multiple Regression Results

\begin{tabular}{|c|c|c|c|c|c|c|c|c|}
\hline \multicolumn{9}{|c|}{ Correlations } \\
\hline & $\mathrm{V}_{0}$ & CGS\% & DML & IT & $\mathbf{e}_{\mathbf{i}}$ & $\mathbf{C I}_{\text {P\&E }}$ & FAT & IMCO \\
\hline $\mathbf{V}_{0}$ & 1.000 & .107 & .102 & .126 & -.056 & .272 & -.230 & -.012 \\
\hline CGS\% & .107 & 1.000 & .073 & .329 & .004 & -.236 & .042 & -.006 \\
\hline DML & .102 & .073 & 1.000 & .032 & -.301 & .023 & -.047 & -.877 \\
\hline IT & .126 & .329 & .032 & 1.000 & .072 & -.150 & .371 & -.010 \\
\hline $\mathbf{e}_{\mathbf{i}}$ & -.056 & .004 & -.301 & .072 & 1.000 & -.039 & .138 & .338 \\
\hline $\mathrm{CI}_{\text {P\&E }}$ & .272 & -.236 & .023 & -.150 & -.039 & 1.000 & -.536 & .003 \\
\hline FAT & -.230 & .042 & -.047 & .371 & .138 & -.536 & 1.000 & .036 \\
\hline IMCO & -.012 & -.006 & -.877 & -.010 & .338 & .003 & .036 & 1.000 \\
\hline \multicolumn{9}{|c|}{ Model Summary $V_{0}=$ dependent variable } \\
\hline Model & $\mathbf{R}$ & $\mathbf{R}^{2}$ & $\Delta \mathbf{R}^{2}$ & SE & df & $\mathbf{F}$ & Sig. & D-W \\
\hline 1 & .404 & .164 & .164 & 23.571 & 7 & 4.307 & .000 & \\
\hline 2 & .403 & .162 & -.002 & 23.513 & 1 & 5.00 & .000 & \\
\hline 3 & .397 & .157 & -.005 & 23.507 & 1 & 5.831 & .000 & 1.282 \\
\hline \multicolumn{9}{|c|}{ Regression Coefficients } \\
\hline & $\mathbf{B}_{\mathrm{U}}$ & SE & $\boldsymbol{B}_{\mathbf{S}}$ & $\mathbf{t}$ & Sig. & $.95 \mathrm{CI}_{\mathrm{L}}$ & $.95 C I_{U}$ & $\mathbf{T}$ \\
\hline Constant & 38.471 & 8.948 & & 4.299 & .000 & 20.794 & 56.147 & \\
\hline CGS\% & 9.887 & 10.344 & .079 & .956 & .341 & -10.547 & 30.322 & .791 \\
\hline DML & 1.988 & .972 & .318 & 2.045 & .043 & .067 & 3.909 & .224 \\
\hline IT & .354 & .155 & .195 & 2.280 & .024 & .047 & .66 & .742 \\
\hline $\mathbf{e}_{\mathrm{i}}$ & -.280 & .570 & -.039 & -.491 & .624 & -1.407 & .847 & .868 \\
\hline $\mathrm{CI}_{\mathrm{P \& E}}$ & 24.207 & 10.461 & .212 & 2.314 & .022 & 3.542 & 44.872 & .644 \\
\hline FAT & -.791 & .420 & -.182 & -1.882 & .062 & -1.620 & .039 & .583 \\
\hline IMCO & 2.168 & 1.180 & .289 & 1.838 & .068 & -.162 & 4.499 & .220 \\
\hline
\end{tabular}

Because of the parsimonious nature of the regression equation, $R^{2}$ as opposed to the adjusted $R^{2}$ was used to evaluate the model's explanatory power. The results of the regression analysis called for rejection of $\mathrm{H}_{0}$ : The regression results indicated the presence of a statistically significant relationship between the set of manufacturing micro-value drivers and shareholder value $\left(V_{0}\right)$, with $\mathrm{e}_{\mathrm{I}}$ being the only micro-value driver to make a clearly insignificant contribution to explained variance. The resulting coefficient of multiple determination $\left(\mathrm{R}^{2}\right)$, which measures the percentage of the variance in shareholder value $\left(V_{0}\right)$ explained by the regression equation was .164, a result that produced an F-ratio of 4.307, which, with seven degrees of freedom, was statistically significant beyond the .001 level. Correspondingly, three micro-value drivers, DML, IT and CIPE had t statistics that were significant at the .05 level and two, FAT and IMCO had t statistics that were significant beyond the .10 level (i.e., .062 and 
.068). Since none of the earlier work pertaining to manufacturing strategy has looked at the extent to which such strategy, specified in terms of the kind of metrics used here, is likely to contribute to the creation of shareholder value, it is impossible to position these results with respect to closely related research. It seems clear, however, that to have 16.4 percent of the variance in $V_{0}$ accounted for by manufacturing based micro-value drivers should be viewed as a result of some significance for manufacturing management.

This analysis identified three micro-value drivers (DML, IT and CIPE) which clearly reside in quadrant IV of the Micro-Value Driver Matrix and that, through active management, would have the potential to contribute in a significant way to the creation of shareholder value. In addition, two micro-value drivers (FAT and IMCO) that would appear to reside in either quadrant III or IV require either active management or close monitoring. By prioritizing the time and efforts of management in this fashion, the kind of "waste" alluded to by Epply (2004) is significantly reduced and better decisions are made in managing those resources and activities directed at influencing variables in quadrants I through III as well. By introducing a regimen whereby important manufacturing micro-value drivers can be identified and their underlying role and significance in creating shareholder value measured, management is provided with a roadmap of where to look to maximize manufacturing's contribution to the overall success of the firm. It also provides a framework within which the kind of methods and metrics broadly utilized by so many companies, like lean manufacturing, can be selectively combined with the proprietary methods and metrics used by most all companies.

For example, maximization of free cash flow to the firm with respect to CGS\% requires optimizing the mix and utilization of direct labor, material and overhead. This objective dictates a focus on the labor versus capital tradeoff, selecting, training and developing talent, compensation that rewards quality, innovation and productivity, design and engineering for lower levels of material intensity and efficient assembly, and achievement of an optimal mix of technology and automation. Such a targeted approach epitomizes what Epply (2004) and Maskell (2007) advocate in eliminating organizational "waste."

With respect to $\mathrm{CI}_{\mathrm{P \& E}}$, some of the decisions made to optimize the mix and utilization of direct labor, material and overhead will, by necessity, impact the process of optimizing the relationship between investment in plant and equipment and revenue derived from that investment. Today the most important of these decisions may well be the "make or buy" decision. At one extreme, optimizing may mean outsourcing for everything, at the other extreme optimization may mean embracing vertical integration. Either way the implications for $\mathrm{CI}_{\mathrm{P} \& \mathrm{E}}$ will be significant. If the decision is to do the work in-house, attention shifts to optimizing systems, processes, the mix of best practices to be used, balancing proximity between suppliers and markets, and technology intensity. If the decision is to outsource the work, selecting suppliers becomes a priority along with designing and implementing a supply chain that provides for optimum flexibility and responsiveness. Capital is freed up as investment in working capital, plant and equipment and people is reduced, which raises the issue of reallocation in terms of both money and talent. Nevertheless, the kind of analysis undertaken here substantially reduces the "waste" that commonly attaches to such changes and in so doing, makes such a strategic undertaking both simpler and easier to justify in terms of the contribution it will make to the creation of shareholder value.

\section{CONCLUSIONS}

The purpose of this research was to determine, in a statistically rigorous manner, whether manufacturing related micro-value drivers could be identified that are statistically significant predictors of a manufacturing firm's market value. Micro-value drivers are manufacturing-related variables over which management has a meaningful level of control that have a determinant influence on a firm's value drivers (i.e., growth in revenue, operating margin, cash tax rate, working capital reinvestment rate, plant and equipment reinvestment rate, and cost of capital). A firm's value drivers are determinant with respect to free cash flow to the firm, intrinsic value and, ultimately, a firm's market value. From a managerial standpoint, understanding which micro-value drivers are determinant and the pathways by which they influence market value facilitates lean manufacturing and makes the task of identifying and actively managing quadrant IV variables (see Figure 1) easier. Shareholder value can be maximized while simultaneously managing non-determinant quadrant 1 through III variables in a less active fashion that nevertheless helps support and sustain value creation. The analysis undertaken here addressed this task by identifying a set of statistically significant quadrant III and IV micro-value drivers and measuring their contribution to the creation of shareholder value among leading manufacturers. It is also a response to White's (1996) early, but as yet unrequited, call for companies and 
academic researchers to utilize new or different measures to assess adequately strategy-related manufacturing performance.

Beyond supporting acceptance or rejection of the null hypothesis, this research provides managerial context by way of the framework for analysis and roadmap for managing micro-value drivers related to manufacturing practices that make the implementation process more efficient. This regimen mandates that management be purposeful in implementing strategy and policy and, in so doing, not waste its time with variables over which it has no control; focusing instead on those variables over which it has both greater control and that are truly determinant with respect to the creation of shareholder value. This does not mean that managers should ignore those factors over which they have little or no control, but that instead they use alternative methods, such as insurance, hedging, and strategic alliances, to manage such exposure. As was suggested earlier, this line of reasoning is similar to, and consistent with, the decision theory underlying management of risk among all kinds of commodities. It is also a line of reasoning that transcends specific initiatives to embrace the way management thinks about such challenges and the extent to which a more open approach obtains where problem-solving is concerned. Again, although the context is different, this is the same kind of reasoning Klee (2005) alludes to in his discussion of "open innovation."

The data were subjected to a simultaneous reverse entry multiple regression analysis, where market capitalization $\left(V_{0}\right)$ was treated as a function of the firm's CGS\%, DML, IT, $\mathrm{e}_{\mathrm{I}}, \mathrm{CI}_{\mathrm{P \& E}}, \mathrm{FAT}$, and IMCO, manufacturing micro-value drivers. The regression model was derived from total, as opposed to incremental variance, with the predictor variables entered in reverse order based on the percentage of total variance accounted for by each variable. This allowed for assessment of the incremental variance explained by each variable, progressing from the least to the most significant predictor variable in terms of explanatory power. Again, market capitalization $\left(V_{0}\right)$ was derived on a year-end basis by multiplying the firm's closing share price by the year-end number of shares outstanding. The results of the regression analysis undertaken here suggest that there is not a statistically significant relationship between the market value of leading manufacturers represented by the top 50 firms from Industrial Week's Annual Survey of Manufacturers and operating performance measured in terms of the following set of manufacturing microvalue drivers: CGS\%, DML, IT, $\mathrm{e}_{\mathrm{I}}, \mathrm{CI}_{\mathrm{P \& E}}$, FAT, and IMCO.

The regression results indicated the presence of a statistically significant relationship between the set of manufacturing micro-value drivers and shareholder value $\left(V_{0}\right)$, with inventory elasticity $\left(\mathrm{e}_{\mathrm{I}}\right)$ being the only variable to make a clearly insignificant contribution to explained variance. The resulting coefficient of multiple determination $\left(\mathrm{R}^{2}\right)$, which measures the percentage of the variance in shareholder value $\left(V_{0}\right)$ explained by the regression equation was .164, a result that produced an F-ratio of 4.307, which, with seven degrees of freedom, was statistically significant beyond the .001 level. Correspondingly, three micro-value drivers - DML, IT and CIPE had t statistics that were significant at the .05 level (i.e., quadrant IV micro-value drivers) and two - FAT and IMCO (i.e., quadrant III/IV micro-value drivers) - had t statistics that were significant beyond the .10 level (i.e., .062 and .068 ). Given the many non-manufacturing influences of shareholder value, to have 16.4 percent of the variance in $V_{0}$ accounted for by manufacturing-based micro-value drivers should be viewed as a result of some significance for manufacturing management. Furthermore, narrowing the strategic focus, with respect to what micro-value drivers should be actively managed and which should not, accommodates Epply's (2004) well regarded appeal for a lean manufacturing orientation with respect to the elimination of manufacturing waste.

From a managerial standpoint, this research provides both context and focus. Context is provided by way of the framework for analysis and roadmap for managing manufacturing micro-value drivers more efficiently. This requires that management be purposeful in implementing strategy and policy and, in so doing, not waste its time with variables over which it has no control, focusing instead on those variables over which it has both greater control and that are truly determinant with respect to the creation of shareholder value. Again, this does not mean that managers should ignore those factors over which they have little or no control but that they use alternative methods, such as insurance, hedging, and strategic alliances, to manage such exposure. As was suggested earlier, this line of reasoning is similar to, and consistent with, the decision theory underlying management of risk among all kinds of commodities. It is also a line of reasoning that transcends specific initiatives to embrace the way management thinks about such challenges and the extent to which a more open approach obtains where problem-solving is concerned. Although the context is different, this is the same kind of thinking Klee (2005) alludes to in his discussion of "open innovation." 
Like the other functional areas of the business, manufacturing performance is ultimately judged in terms of its incremental contribution to free cash flow to the firm. Extrapolating from the results of this analysis, control of those activities that directly impact cost of goods sold relative to growth in sales, inventory control (i.e., finished goods, work in process and material) and capital investment in plant, equipment and related technology relative to sales, should be chief priorities. The extent to which these priorities are effectively met will, in turn, be reflected in the firm's operating margin, reinvestment rate for plant, equipment and related technology, and the firm's cost of capital. Manufacturing's incremental contribution to this process can only be maximized through management's unswerving focus on the labor versus capital tradeoff, selecting, training and developing talent, compensation that rewards quality, innovation and productivity, design and engineering for lower levels of material intensity and efficient assembly, achievement of a optimal mix of technology and automation, and the right level of vertical integration. The model developed here facilitates such a targeted approach by helping transform what would otherwise be a complex multifaceted problem into a more manageable set of clearly articulated relationships and resources that are inextricably linked to the creation of shareholder value.

Though this research allows one to have confidence in the notion that manufacturing done right can make a direct, meaningful contribution to the creation of shareholder value, it is important to not overstate what has been learned. Here 16.4 percent of the total variance in market value was explained by the regression model, a statistically significant result, but a result nevertheless that still leaves over 80 percent of the variance in market value unexplained. Disaggregating this unexplained variance would appear to represent a rich opportunity for future research. In addition, by expanding the sample size, one could effectively measure the interactive effects of industry and location on the various micro-value drivers, as well as more effectively accounting for the distinction between assemblers and manufacturers. Here one could argue that capital intensity is a meaningful, though somewhat indirect, measure of the inherent nature of a firm; however, creation of a categorical measure would be a more direct and probably more efficient measure of such differences. In any event, these additional research opportunities represent avenues for gaining a more complete understanding of the contribution manufacturing makes to the creation of shareholder value and indirectly help position the current research with respect to the existing body of knowledge pertaining to the measurement and evaluation of manufacturing performance.

\section{AUTHOR INFORMATION}

Dr. Waldron is a member of the business faculty at Trinity University where he teaches Business Policy and International Management. In addition to his commitment to teaching, Dr. Waldron has compiled an extensive record of scholarship by publishing in an array of peer reviewed journals, complemented by numerous conference presentations and scholarly papers of both a domestic and international nature.

\section{REFERENCES}

1. Bartlett, C. A. and S. Ghoshal (1989). Managing across borders: The transnational solution, Harvard Business School Press: Boston, MA.

2. Barry, C. (2007). The best of inventory, Multi Channel Merchant: Best Inventory Strategies, http://multichannelmerchant.com/opsandfulfillment/best inventory 012007/.

3. Brown, S. and J. Bessant (2003). The manufacturing strategy-capabilities links in mass customization and agile manufacturing-an exploratory study, International Journal of Operations \& Production Management, Vol. 23, Issue 7, 707 - 730.

4. Chan, K. C. (1993). Intelligent corporate strategy: Beyond world-class manufacturing, Industrial Management \& Data Systems Journal, (93), (2), 1 - 64.

5. Chen, C. C. (2008). An objective-oriented and product-line-based manufacturing performance measurement, International Journal of Production Economics, Volume 112, Issue 1, March, 380 - 390.

6. Copeland, T., T. Koller and J. Murrin (2000). Valuation: Measuring and managing the value of companies, John Wiley and Sons, Inc., New York.

7. Christopher, M. and L. Ryals (1999). Supply chain strategy: Its impact on shareholder value, The International Journal of Logistics Management, Vol. 10, Issue 1, 1 - 10. 
8. Cua, K., E. McKone and R. G. Schroeder (2001). Relationships between implementation of TQM, JIT, and TPM and manufacturing performance, Journal of Operations Management, Volume 19, Issue 6, November 2001, Pages 675 - 694.

9. Drucker, P. (1990). The emerging theory of manufacturing, Harvard Business Review, May-June, 94 - 102.

10. Epply, T. (2004). The lean manufacturing handbook, second edition, http://continental-design.com/leanmanufacturing/handbook-1.html.

11. Fry, T. D. (1992). Manufacturing performance and cost accounting, Production and Inventory Journal, Volume 33 (3): 30 - 35.

12. Ghalayini, A. M., J. S. Noble and T. J. Crowe (1997). An integrated dynamic performance measurement system for improving manufacturing competitiveness, International Journal of Production Economics, Volume 48, Issue 3, February 14, 207-225.

13. Hair, J. F. Jr., R. E. Anderson, and R. L. Tatham (1987). Multivariate data analysis, second edition, Macmillan Publishing Company, New York: New York.

14. Harrison, A. (1998). Manufacturing strategy and the concept of world class manufacturing, International Journal of Operations and Production Management, Vol. 18, Issue 4, 397 - 408.

15. Hayes, R. H. and G. P. Pisano (1994). Beyond world-class: The new manufacturing strategy, Harvard Business Review, 1-13.

16. Nilsson F. and M. Kald. (2005). Performance measurement at nordic companies, European Management Journal, Volume 23, Issue 6, December, 113 - 127.

17. Klee, K. (2005). Rewriting the rules in R\&D, The Deal.Com, July 1, http://www.thedeal.com/corporatedealmaker/2005/02/rewriting_the_rules_in_rd.php.

18. Maskell, B. H. (2007). Lean accounting - Beyond the back office, http://www.superfactory.com/articles/featured/2007/0712-maskell-lean-accounting-back-office.html.

19. Maskell, B. H. (1991). Performance measurement for world class manufacturing: A model for American companies, Productivity Press, London.

20. Martin, A. D. and Mauer L. J. (2003). Transaction versus economic exposure: Which has greater cash flow consequences? International Review of Economics and Finance, (12), 4, 437 - 449.

21. McCrea, B. (2006). World class inventory management - Beyond cost reduction to strategic advantage, Supply Chain Management Review, September 13, http://www.scmr.com/article/CA6371601.html.

22. Merkel, K. G. (1995). Achieving planned performance results using manufacturing operations, Industrial Engineering, 27 (4): 26 - 29.

23. Namasivayam, K. and D. Basak (2006). Human capital in service organizations: Identifying value drivers, Journal of Intellectual Capital, 381-393.

24. Paranjape, B., M. Rossiter and V. Pantano (2006). Performance measurement systems success, failures and future - a review, Measuring Business Excellence, Volume 10, Issue, 3, 4 - 14.

25. Parmenter, David (2007). Key performance Indicators, John Wiley \& Sons.

26. Rappaport, A. (1998). Creating shareholder value: A guide for managers and investors, The Free Press, 171 179.

27. Roth, A. V. and J. G. Miller. (1992). Success factors in manufacturing, Business Horizons, $35(4)$ : 73 - 81.

28. Roztocki, N. and K. L. Needy (1999). Integrating activity-based costing and economic value added in manufacturing, Engineering Management Journal, Volume 11, 17 - 22.

29. Schroeder, R. G., K. A. Bates and M. A. Junttila (2002). A resource-based view of manufacturing strategy and the relationship to manufacturing performance, Strategic Management Journal, Vol. 23, No. 2, 105-117.

30. Shah, R. and P. T. Ward (2003). Lean manufacturing: context, practice bundles, and performance, Journal of Operations Management, Volume 21, Issue 2, March, 129 - 149.

31. SoftStat Electronic Text, http://www.uta.edu/faculty/sawasthi/Statistics/stdiscan.html.

32. Son, Y. K. and C. S. Park (1987). Economic measure of productivity, quality and flexibility in advanced manufacturing systems, Journal of Manufacturing Systems, Volume 6, Issue 3, 193 - 207.

33. Sweeney, M. T. (1994). Benchmarking for strategic manufacturing management, International Journal of Operations \& Production Management, Vol. 14, Issue 9, 4 - 15.

34. White, G. P. (1996). A survey and taxonomy of strategy-related performance measures for manufacturing, International Journal of Operations \& Production Management, Vol. 16, Issue 3, 42-61.

35. Wise, R. and P. Baumgartner (2007). Go downstream: The new profit imperative in manufacturing, http://harvardbusinessonline.hbsp.harvard.edu/hbsp/hbr/articles/. 